\title{
Los juicios de proporcionalidad en la teoría moral y jurídica de la escolástica española aurisecular
}

Proportionality judgments in moral and legal theory of the aurisecular Spanish scholasticism

Alejandro Miranda Montecinos

Universidad de los Andes, Chile amiranda@uandes.cl

DOI: https://doi.org/10.15366/bp2021.26.001 Bajo Palabra. II Época. No26. Pgs: 21-38 
Recibido: 20-08-2020

Aceptado: 21-09-2020

\section{Resumen}

En este trabajo se estudian los criterios utilizados por los moralistas y juristas de la escolástica española (siglos XVI y XVII) para efectuar juicios de proporcionalidad. El autor procura mostrar que los escolásticos efectuaron importantes aportes para el desarrollo de una teoría que, reconociendo la inconmensurabilidad de los bienes y males humanos fundamentales, acepta que es posible realizar comparaciones que permitan hablar de bien (o mal) mayor o de bien (o mal) menor.

Palabras clave: proporcionalidad, derechos, comparación de bienes y males.

\section{Abstract}

This work analyzes the criteria used by the moralists and jurists of Spanish scholasticism (16th and 17th centuries) to carry out proportionality judgments. The author tries to show that the scholastics made important contributions to the development of a theory that, recognizing the incommensurability of fundamental human goods and evils, accepts that it is possible to make comparisons that allow us to speak of greater good (or evil) or lesser good (or evil).

Keywords: proportionality, rights, comparison of goods and evils. 


\section{Introducción}

El PROBLEMA DE LOS JUICIOS DE PROPORCIONALIDAD ha sido ampliamente discutido en la filosofía jurídica de las últimas décadas. El debate ha alcanzado su mayor sofisticación a propósito de la denominada interpretación proporcionalista de los derechos fundamentales, defendida principalmente por Robert Alexy. Este autor postula que el recurso a los juicios de proporcionalidad es necesario para una adecuada teoría sobre la solución de conflictos prima facie entre derechos fundamentales o entre los principios jurídicos que los consagran.

En este trabajo se analizarán las tesis defendidas por algunos moralistas y juristas de la escolástica española (s. XVI y XVII) acerca de los juicios de proporcionalidad. Lo que se pretende mostrar es que los escolásticos efectuaron importantes aportes para el desarrollo de una teoría que, reconociendo la inconmensurabilidad de los bienes y males humanos fundamentales, acepta que es posible realizar comparaciones que permitan hablar de bien (o mal) mayor o de bien (o mal) menor.

El plan que guía esta investigación es el siguiente. En primer lugar, se explicará el contexto en el que los autores escolásticos se plantearon el problema de los juicios de proporcionalidad y el alcance que les atribuyeron. En segundo lugar, se mostrará cómo se articula la teoría escolástica sobre los juicios de proporcionalidad. Para esto se la relacionará con algunos elementos de la más extendida teoría filosófico-jurídica sobre la misma materia: el proporcionalismo de Robert Alexy. En tercer lugar, se analizarán las tesis de los escolásticos sobre la proporcionalidad en sentido estricto. Finalmente, se examinarán, en particular, los criterios para evaluar la gravedad de los bienes y de los males en sí mismos.

\section{Contexto y alcance de los juicios de proporcionalidad en la escolástica española}

LOS AUTORES ESCOLÁSTICOS REFLEXIONARON SOBRE LOS JUICIOS DE PROPORCIONALIDAD principalmente en el contexto de la evaluación moral de acciones con efectos colaterales o indirectos. Cuando se sabe que la acción necesaria para conseguir un bien producirá igualmente, como efecto colateral, un mal significativo, surge un conflicto para el agente: o ejecuta la acción para conseguir el bien, o se abstiene de 
ella para evitar el mal. La tradición escolástica sostiene que una acción de este tipo solo está moralmente justificada si existe una razón proporcionalmente grave para realizarla. Esto significa que el bien que se quiere conseguir mediante la acción debe al menos compensar al mal que se va a producir como efecto indirecto. Como el bien que se busca puede consistir en la evitación de un mal, y como todo mal consiste en la privación de un bien, el juicio sobre la proporcionalidad exige una comparación entre los bienes y una comparación entre los males.

Los juicios de proporcionalidad, por tanto, son relevantes principalmente para evaluar acciones de las que se siguen efectos colaterales malos. Ningún autor escolástico sostiene que dichos juicios tengan relevancia suficiente para derrotar cualquier otra consideración al momento de evaluar la bondad o malicia de las acciones. Los moralistas y juristas escolásticos no son utilitaristas, consecuencialistas o proporcionalistas. Según el proporcionalismo moral, el juicio de proporcionalidad es el criterio exclusivo o supremo de la evaluación moral. Por el contrario, todos los escolásticos - herederos como son de la tradición tomista de la ley naturalreconocen la existencia de actos intrínsecamente malos que ningún cálculo de utilidad o juicio de proporcionalidad puede justificar. Los actos intrínsecamente malos pueden definirse con independencia del juicio de proporcionalidad, pues dependen del modo en que la voluntad humana se relaciona con ciertos bienes o males específicos. Por ejemplo, el homicidio, en cuanto acto intrínsecamente malo, no consiste simplemente en matar a un individuo humano, ni tampoco en matar a un individuo humano sin razón proporcionada, sino en matar intencionalmente a un ser humano inocente.

La diferencia entre una doctrina como la de los escolásticos y el proporcionalismo moral puede apreciarse con claridad al evaluar situaciones extremas, como las que suelen plantearse en los casos de amenazas de tiranos o chantajes de terroristas. Domingo de Soto, por ejemplo, trata el caso que se produce cuando "en el asedio que un tirano pone a una ciudad, hay una persona inocente, cuya cabeza pide el

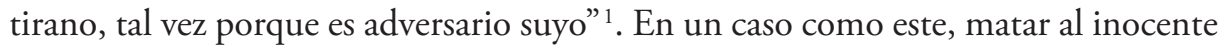
sería un medio para evitar enormes males, como la muerte de muchos otros inocentes o incluso la destrucción de la ciudad completa. Sin embargo, los escolásticos afirman de modo unánime que tal acción no se justificaría. Puesto que matar a un inocente como medio para un fin es un acto intrínsecamente malo, no procede efectuar ningún juicio de proporcionalidad al respecto. Un proporcionalista, en cambio, resolvería el caso de modo distinto. Así, el teólogo proporcionalista Charles

\footnotetext{
${ }^{1}$ Soto, Domingo de, De iustitia et iure, 1. 5, q. 1, a. 7. Las referencias a las obras de los escolásticos se realizan de acuerdo con sus propias divisiones internas, como es usual entre los especialistas. En la Bibliografía se consignan las diversas ediciones consultadas.
} 
Curran, ante un caso análogo al planteado por Soto, propone aceptar la regla "matar directamente al inocente es malo, excepto en los casos en que uno tiene la certeza de que ése es el único modo de salvar a un número mayor de inocentes" ${ }^{2}$. Luego, si en el caso del tirano concurre esta certeza, se justificaría, según Curran, matar al inocente como medio para que el tirano se abstenga de matar a otros muchos.

\section{Idoneidad, necesidad y proporcionalidad en sentido estricto}

EN ESTE APARTADO MOSTRARÉ CÓMO SE ARTICULA LA TEORÍA ESCOLÁSTICA SObre los juicios de proporcionalidad. Para ello la relacionaré con algunos elementos de la teoría de Robert Alexy. Dado que este autor trata la materia más sistemáticamente, la comparación puede favorecer la comprensión de las ideas escolásticas. Luego de una breve explicación de las líneas generales de la teoría de Alexy, pasaré al análisis de los aportes escolásticos.

Alexy sostiene que los juicios de proporcionalidad son necesarios para resolver satisfactoriamente los casos de colisión entre dos principios jurídicos que consagran derechos fundamentales. Los principios de este tipo suelen tener la forma "Todas las personas tienen derecho a la vida", "Todas las personas tienen derecho a la libertad de conciencia", etc. Es decir, son enunciados cuya estructura hace frecuente la colisión. A diferencia de lo que sucede en los conflictos entre reglas, dos principios en colisión pueden continuar siendo simultáneamente válidos respecto de un mismo caso. Esto se debe a que los principios son mandatos de optimización: ellos se pueden cumplir en diversos grados, pues mandan que algo sea realizado en la mayor medida posible, dentro de las posibilidades fácticas y jurídicas existentes. Las posibilidades jurídicas están determinadas por las reglas y por otros principios contrapuestos. En caso de colisión, entonces, no se debe determinar cuál de los principios es válido y cuál no lo es, sino qué principio prima sobre el otro en ese caso concreto. Esta determinación se hace por recurso a la ponderación. Es decir, mediante la ponderación se determina el grado adecuado de satisfacción de un principio en relación con lo exigido por otros principios ${ }^{3}$.

Para efectuar la ponderación se ha de recurrir al principio de proporcionalidad. El principio proporcionalidad consta de tres subprincipios: el principio de idoneidad, el principio de necesidad y el principio de proporcionalidad en sentido

${ }^{2}$ Curran, Charles, "Utilitarismo y moral contemporánea", trad. de J. L. Zubizarreta, Concilium, 120, 1976, pp. 583-605, en p. 588.

3 Alexy, Robert, "Los derechos fundamentales y la proporcionalidad", trad. de Renate Hoffmann, en id., Ensayos sobre la teoría de los principios y el juicio de proporcionalidad, Lima, Palestra, 2019, pp. 237-250. 
estricto. Los dos primeros se refieren a la optimización con respecto a las posibilidades fácticas; el tercero se refiere a la optimización con respecto a las posibilidades jurídicas. El principio de idoneidad establece que no se deben utilizar medios que, sin ser aptos para beneficiar la realización de un principio, limiten además la realización de otro principio. El principio de necesidad establece que, de dos medios igualmente idóneos para beneficiar la realización de un principio, se debe elegir el que menos limite la realización de otros principios. El principio de proporcionalidad en sentido estricto establece, por último, que cuanto mayor sea el grado de no satisfacción o de afectación de un principio, tanto mayor debe ser la importancia de la satisfacción del otro ${ }^{4}$.

La estructura de la ponderación se describe de modo más preciso en lo que Alexy llama "fórmula del peso", que consiste en una ecuación que permite determinar el peso concreto de un principio en relación con otro principio con el cual entra en colisión. Dicho peso es el cociente, esto es, el resultado de la división, de tres factores a cada lado de la ponderación. Los tres factores que componen el dividendo son (i) la intensidad de la injerencia en el principio 1, (ii) el peso abstracto del principio 1 y (iii) la seguridad de los supuestos empíricos y normativos relevantes respecto del principio 1 (intensidad de la injerencia y peso abstracto). Los tres factores que componen el divisor son, a su vez, (i) la importancia de la satisfacción del principio 2, (ii) el peso abstracto del principio 2 y (iii) la seguridad de los supuestos empíricos y normativos relevantes respecto del principio 2 . Todos estos factores deben poder reducirse a números. Con este fin, Alexy propone una escala que asigna los rangos de "leve", "moderado" y "grave" a los dos primeros factores y los rangos de "cierto", "plausible" y "no evidentemente falso" al tercero. Estos valores son expresados por los números 1,2 y 4 .

Pues bien, aunque Alexy explica su teoría en relación con la realización o afectación de principios jurídicos o derechos fundamentales, las mismas ideas pueden expresarse en términos de bienes y males. A fin de cuentas, los principios jurídicos y los derechos fundamentales se refieren siempre a ciertos bienes humanos, lo que justifica esta modificación para efectos analíticos.

Si traducimos al lenguaje de los bienes los tres subprincipios propuestos por Alexy, nos resulta algo como lo siguiente. El principio de idoneidad establece que no se debe utilizar un medio que, sin ser idóneo para alcanzar un bien, produzca además un mal. El principio de necesidad establece que, entre dos medios igualmente idóneos para alcanzar un bien, se debe optar por el que produzca menos mal.

${ }^{4}$ Ibid.

5 Alexy, Robert, "La dignidad humana y el juicio de proporcionalidad", trad. de María Quimbayo, en ibid., pp. 281-295. 
El principio de proporcionalidad en sentido estricto establece que, cuanto mayor sea el mal que un medio provoque, tanto mayor debe ser el bien que ese medio permita alcanzar. Lo que intentaré mostrar a continuación es que estos principios, como de sentido común que son, ya estaban presentes en las obras de los autores escolásticos. Para hacerlo me valdré de lo que enseña Francisco de Vitoria sobre lo que, en lenguaje actual, podríamos llamar "protección de la población civil en los conflictos armados".

En su tratamiento del ius in bello, Vitoria se pregunta si puede ser lícito matar inocentes. Su respuesta exige distinguir entre dos formas distintas de matar: (i) per se y ex intentione y (ii) per accidens y praeter intentionem. Se mata per se y ex intentione cuando se busca la muerte como fin de la acción o como medio para alcanzar otro fin. Se mata per accidens y praeter intentionem cuando no se busca la muerte ni como fin ni como medio para alcanzar un fin, sino que solo se acepta como un efecto colateral de una acción que se dirige a otro fin. A la luz de esta distinción, Vitoria sostiene que "nunca es lícito matar inocentes per se y ex intentione" ${ }^{6}$. O sea, si se trata de un acto de matar ex intentione, la malicia o injusticia de matar al inocente queda establecida de plano, con prescindencia de cualquier juicio de proporcionalidad. Más aún: toda ponderación o juicio de proporcionalidad sería en este caso derechamente improcedente, pues matar intencionalmente a una persona inocente es un acto intrínsecamente malo. Distinto es el caso si se trata de un acto de matar praeter intentionem o per accidens. En efecto, "per accidens, algunas veces es lícito matar inocentes incluso a sabiendas, como cuando se ataca justamente una fortaleza o una ciudad, en la cual consta que hay muchos inocentes, y no pueden emplearse máquinas de guerra, ni armas arrojadizas, ni prenderse fuego a los edificios, sin que padezcan tanto los inocentes como los nocentes" ${ }^{7}$. Esto quiere decir que, para defenderse de los agresores o nocentes, es lícito realizar acciones que resulten occisivas también para los inocentes, siempre que la muerte de estos últimos esté fuera de la intención, esto es, no sea buscada ni como fin ni como medio.

Pero para la licitud de esta acción no basta con la rectitud de intención. La rectitud de intención es una condición necesaria pero no suficiente de la justificación moral. Se requiere también, en este caso, un juicio de proporcionalidad que arroje un resultado favorable. Y aquí podemos ver que Vitoria emplea criterios semejantes a los del proporcionalismo jurídico. Esto no es algo sorprendente, porque, al menos entendidos en su sentido general, los tres principios mencionados por el proporcionalismo jurídico no son más que expresiones de juicios de sentido común.

\footnotetext{
${ }^{6}$ Vitoria, Francisco de, De iure belli, n. 35.

7 Vitoria, Francisco de, De iure belli, n. 37; Commentaria in secundam secundae, q. 40, a. 1, n. 11; q. 64, a. 2, n. 10 ; q. 64 , a. 6 , n. 6.
} 
Para que se cumpla con la debida proporcionalidad se requiere, según Vitoria, que la acción de la que se sigue la muerte de los inocentes sea necesaria para alcanzar el buen fin al que se dirige, esto es, expugnar la fortaleza enemiga o defenderse de los agresores. Si dicha acción no es necesaria, porque existe otra vía menos perjudicial que asegura el triunfo en la guerra, no estará moralmente justificada. Por eso escribe Vitoria que "nunca parece lícito matar inocentes, incluso per accidens y praeter intentionem, sino cuando la guerra justa no puede desenvolverse de otro modo" Cuando la guerra sí puede desenvolverse de otro modo, se debe optar por él, en el entendido de que se trata de un modo que produce menos mal.

Vitoria no se refiere explícitamente al principio de idoneidad, pero eso no significa que lo hubiera rechazado. Al contrario, ocurre más bien que el principio de idoneidad es tan obvio que puede resultar superfluo mencionarlo de modo explícito. En efecto, si un curso de acción no sirve para alcanzar un fin, no es en absoluto un medio, y debería descartarse de la deliberación. Alexy — como vimos — sostiene que la vía no idónea debe prohibirse jurídicamente si además lesiona otros bienes. La ética es en esto más exigente, pues prohíbe la vía no idónea aun cuando de ella no se siga daño alguno: simplemente no es razonable intentar conseguir un fin por una vía que no permite alcanzarlo. En cualquier caso, el cumplimiento del principio de necesidad supone el cumplimiento del principio de idoneidad, pues un medio no puede ser necesario para alcanzar un fin si no es, ante todo, idóneo para alcanzarlo.

Pero Vitoria sí se refiere explícitamente a la proporcionalidad en sentido estricto, esto es, a la proporción entre los bienes y los males que se seguirán de la acción. Si la acción producirá un mal significativo, como la muerte de personas inocentes, debe permitir alcanzar un bien de mucha importancia, como la victoria de la guerra. Así, afirma el teólogo que "si para conseguir la victoria principal en una guerra, representa poco el atacar una fortaleza o una ciudad en que hay guarnición enemiga, y hay allí muchos inocentes, no parece lícito que para combatir a unos pocos nocentes se pueda matar a muchos inocentes" .

\section{La proporcionalidad en sentido estricto en los escolásticos de los siglos XVI y XVII}

De las tres Clases de proporcionalidad, la que presenta problemas filosóficos más complejos es la proporcionalidad en sentido estricto. Las dificultades que

\footnotetext{
${ }_{8}^{8}$ Vitoria, Francisco de, De iure belli, n. 37.

9 Vitoria, Francisco de, De iure belli, n. 37.
} 
existen acerca de la posibilidad de conmensurar o, incluso, de comparar bienes humanos heterogéneos y diversos entre sí ha llevado a muchos autores a mirar con escepticismo los resultados de la ponderación o el balance de bienes humanos.

En los escolásticos de los siglos XVI y XVII no se encuentra un desarrollo sofisticado del tema, pero sí hay elementos que permiten alguna sistematización. Estos autores no se plantearon explícitamente el problema de la existencia de una jerarquía objetiva de bienes humanos ni tampoco el de la posibilidad de conmensurar los distintos bienes humanos fundamentales. No obstante, hicieron aportes interesantes que podrían ordenarse del siguiente modo.

Los moralistas escolásticos convienen en que el juicio de proporcionalidad solo puede realizarse prudencialmente, y no pude determinarse por una regla que tenga pretensiones de alcanzar certeza. Tomás Sánchez, por ejemplo, al tratar acerca de la causa proporcionada para realizar una acción que posibilitará o facilitará males morales ajenos, sostiene que "ninguna cantidad cierta de aquella causa se puede prescribir por una regla, sino que se debe remitir al arbitrio del prudente" ${ }^{10}$. Del mismo modo, Domingo de Santa Teresa, refiriéndose ahora a la gravedad de la necesidad que debe concurrir, en general, para realizar una acción de la que se sigue cualquier tipo de males, afirma que esa gravedad "no se puede determinar por una regla general, pues se ha de filosofar de diverso modo según las diversas materias y causas" ${ }^{11}$.

A pesar de lo anterior, los moralistas escolásticos también convienen en que es posible señalar algunos criterios generales válidos para evaluar la proporcionalidad en todos los casos. El mismo Tomás Sánchez añade que "para que ese arbitrio sea prudente, debe atender a que se requiere una causa tanto mayor cuanto más grave es el pecado al cual aquella ayuda da ocasión, y cuanto de modo más próximo se relaciona con él, o de suyo está más determinada al mal, y cuanto más cierto es que se seguirá el pecado como efecto, y cuanto más probable es que será impedido el pecado si no se ayuda" ${ }^{12}$. (Las menciones al "pecado", propias del lenguaje de la teología moral, podrían reemplazarse aquí, sin cambio en la idea esencial, por menciones a "malas acciones" o, más en general, simplemente a "males"). Domingo de Santa Teresa, influido por Sánchez, continúa su exposición de modo semejante: “... en cualquier materia se exige una mayor necesidad para excusar la permisión del mal donde el mal permitido es en sí mismo más grave, donde la causa le es más próxima, donde está más determinada a tal mal, donde se prevé con más seguridad

\footnotetext{
10 Sánchez, Tomás, Opus morale in praecepta Decalogi, 1. 1, c. 7, n. 12.

${ }^{11}$ Collegii salmanticensis ff. discalceatorum b. Mariae de Monte Carmeli primitivae observantiae, Cursus theologicus, tr. 13, disp. 10, dub. 6, par. 5, n. 244.

12 Sánchez, Tomás, Opus morale in praecepta Decalogi, 1. 1, c. 7, n. 12.
} 
que este se seguirá en el futuro y donde hay menos vías para impedirlo después de que se ha puesto la causa"13.

En los pasajes de Sánchez y de Domingo de Santa Teresa aparecen elementos comunes: para que se cumpla con la debida proporcionalidad se requiere que el bien que se busca conseguir o el mal que se busca evitar o impedir mediante la acción sean tanto mayores cuanto (i) más grave sea el mal que de esa acción se seguirá, (ii) de modo más próximo se siga ese mal de la acción, (iii) más determinada esté la acción a producir el mal, (iv) mayor sea la probabilidad o certeza de que dicho mal efectivamente se producirá si se realiza la acción y (v) mayor sea la probabilidad o certeza de que dicho mal no se producirá si la acción se omite. Los factores (ii) y (iii), esto es, proximidad del mal respecto de la acción y determinación de la acción al mal, parecen poder reducirse siempre al factor (iv), es decir, a la probabilidad de ocurrencia del mal. En efecto, si un mal se sigue más remotamente de la acción, pero se sigue con más certeza, contará más que si se sigue de modo más próximo con menor seguridad. Y si ambos males se siguen con igual probabilidad o certeza, la mayor o menor proximidad se torna irrelevante en sí misma. La mayor o menor proximidad puede ser relevante por los efectos que produce en otros sujetos ( $v . \mathrm{gr}$., mayor o menor riesgo de escándalo), pero en tal caso se trataría de otros males que se siguen de la acción y que deberían ser considerados en el juicio de proporcionalidad de forma independiente, incluyendo su propia gravedad, su propia probabilidad de ocurrencia, etc.

Domingo de Santa Teresa destaca la relevancia de considerar la gravedad del mal en sí mismo. Con esto se refiere, probablemente, a considerar la gravedad del mal con independencia de los restantes factores que señala a continuación (proximidad, seguridad, etc.). Pero hay otro sentido en que puede entenderse la expresión en si mismo, que es muy importante para los juicios de proporcionalidad. Dicha expresión puede considerarse como contrapuesta a en relación con el agente. En efecto, un adecuado juicio de proporcionalidad debe tomar en cuenta no solo la importancia del mal considerado en sí mismo, sino también la importancia del mal en relación con el agente. Esta última perspectiva exige atender a los deberes específicos de la persona que actúa, deberes que derivan de su estado, oficio o, en general, de compromisos previos por ella adquiridos ${ }^{14}$. Los escolásticos también reparan en que, para evaluar la importancia de los bienes o de los males, es fundamental tomar en cuenta los deberes específicos que tiene el agente de conseguir los primeros o de evi-

${ }_{13}$ Collegii salmanticensis, Cursus theologicus, tr. 13, disp. 10, dub. 6, par. 5, n. 247.

${ }^{14}$ La distinción entre juzgar la importancia de los bienes y males en sí mismos y juzgarlos en relación con el agente equivale a la que en la ética contemporánea se suele trazar entre "análisis de agente neutral" y "análisis relativo al agente”. Véase Nagel, Thomas, The View from Nowhere, New York, Oxford University Press, 1986, pp. 175-185. 
tar los segundos. Así, Enrique de Villalobos señala que el oficio del agente o algún contrato (concierto) que haya celebrado pueden obligarlo a aceptar males que para otras personas serían desproporcionados. Por ejemplo, el corregidor está obligado a permanecer en la ciudad en tiempo de peste, aun a riesgo de perder la vida, mientras que otros ciudadanos no tienen esa obligación ${ }^{15}$.

El criterio según el cual el bien que se busca con la acción ha de ser tanto mayor cuanto mayor sea el grado de probabilidad o certeza de que los males en juego efectivamente se producirán fue destacado también por Francisco de Vitoria. Así, el dominico sostiene que "no es lícito navegar, con peligro manifiesto e inminente, cuando esto se hace por un negocio particular ordenado a aumentar la hacienda familiar; pero es lícito por el bien de la república — como, por ejemplo, para liberar a la comunidad - o por la fe" ${ }^{16}$. En cambio, "cuando se trata de aquel peligro ordinario sin el cual no puede realizarse la navegación, es lícito navegar, pues de lo contrario perecería el comercio" ${ }^{17}$.

Uno de los criterios de más relevante aplicación en la doctrina de los escolásticos es aquel conforme al cual el bien que se busca conseguir o el mal que se busca impedir mediante la acción deben ser tanto mayores cuanto mayor sea la probabilidad o certeza de que el mal que se prevé como efecto de esa acción no se producirá si ella se omite. Dicho de modo más simple, este criterio dice que el agente tiene mayor razón para realizar la acción cuanto más seguro sea que no se evitará el efecto malo si se abstiene de ella. Francisco Suárez, por ejemplo, recurre a este criterio para justificar la acción de la mujer embarazada que toma un remedio necesario para conservar su vida a sabiendas de que causará también, como efecto colateral, la muerte del feto. Según Suárez esta acción es proporcionada porque "si se permite la muerte de la madre, en la mayoría de los casos moriría también el hijo; luego, es mejor, si es posible, salvar la vida de la madre permitiendo la muerte del hijo, antes que permitir la muerte de ambos" ${ }^{18}$. El mismo criterio aplica Juan Azor para defender que es lícito a una mujer embarazada huir corriendo para salvarse del fuego, de un torrente de agua, de la cólera de un enemigo o de un ataque bélico, aun cuando esto pueda implicar la muerte del feto. En estos casos — argumenta Azor- puede estimarse que la madre cuenta con una razón proporcionada para actuar, pues "si no corre y huye se exponen al peligro de muerte tanto la madre como el feto" ${ }^{19}$.

\footnotetext{
15 Villalobos, Enrique de, Summa de la theologia moral y canonica, p. 2, tr. 12, dif. 7, conc. 2.

${ }^{16}$ Vitoria, Francisco de, Commentaria in secundam secundae, q. 64, a. 5, n. 9.

17 Ibid.

18 Suárez, Francisco, Commentaria in secundam secundae divi Thomae, scilicet de fide, de spe et de charitate disputationes, tr. 3, disp. 13, sec. 7, n. 19.

19 Azor, Juan, Institutionum moralium, pars 3, 1. 2, c. 3, quaerit. 22.
} 


\section{Criterios para evaluar la gravedad de los bienes y de los males en sí mismos}

El ANÁLISIS DE LOS ESCOLÁsticos no termina con lo que acabamos de exponer. También desarrollan criterios para evaluar la gravedad de los bienes y de los males en sí mismos. El criterio que más claramente invocan en este punto es el de la primacía del bien común por sobre el bien particular. Así, Domingo Bánez, al tratar acerca de la proporcionalidad de las acciones que producen efectos colaterales malos, dice lo siguiente: “... cuando la acción en sí misma buena, de la cual se sigue algún efecto en sí mismo ilícito, o nocivo respecto de otro, me es sin embargo necesaria para la conservación de aquello a lo que tengo derecho, me es lícito perseverar en aquella buena acción, con tal de que el efecto que de ella se sigue per accidens no sea notablemente nocivo para el bien común. Y mucho más será lícito persistir en aquella acción cuando ella promueve el bien común" ${ }^{20}$. Por cierto, este criterio es todavía muy general. Él nos permite concluir, por ejemplo, que es razonable enviar soldados a la guerra, a pesar de que se pueda prever que muchos morirán en ella. Pero hay cuestiones que no resuelve. Así, es claro que no cualquier promoción del bien común constituye una justificación para realizar acciones que dañen bienes particulares: la ponderación de bienes y males según otros criterios siempre será necesaria. Del mismo modo, determinar si algo es notablemente nocivo para el bien común nos remite nuevamente a la cuestión de cómo determinar la magnitud de los males y bienes.

Un segundo criterio para evaluar la gravedad de los males y de los bienes en sí mismos es el de la primacía de la persona, y podría formularse así: los bienes y los males humanos son más importantes o graves que los bienes y males de los seres subhumanos. Es tesis común de los escolásticos que las realidades subhumanas están subordinadas al bien de las personas. Como los seres irracionales, sean animados o inanimados, no son sujetos de derechos, es lícito que los hombres los usen como instrumentos. Vitoria lo expone claramente: “... es algo cierto que no se les hace injusticia (injuria) a los animales brutos, incluso si se les mata. Los brutos no son capaces de [padecer] injusticia, porque en sí mismos no tienen derechos (non habent jus in se). Pero un hombre sí tiene derechos. Pues hemos dicho que solo una naturaleza racional es capaz de dominio. Solo el hombre es dueño de sí mismo y de sus miembros, y no los brutos. Así, la piedra no es dueña de sí misma, ni lo es el ciervo, y, tal como no se hace ninguna injusticia a las piedras cuando se las rompe, tampoco se les hace a las plantas cuando se arrancan, ni a los árboles cuando se cortan, ni tampoco a los brutos

${ }^{20}$ Báñez, Domingo, Decisiones de iure et iustitia, q. 64, a. 7, dubit. 5. 
cuando se les mata" ${ }^{21}$. De esto se sigue, naturalmente, que en los juicios de proporcionalidad los bienes y males humanos son más importantes que los de las realidades subhumanas. Esto también implica, por cierto, que bienes como la vida, la salud y la integridad física de las personas son más valiosos que los bienes de fortuna. No obstante, como los bienes de fortuna se ordenan finalmente a bienes humanos básicos, la preferencia de estos por sobre aquellos rige solo en general. En efecto, en ciertos casos un daño muy pequeño a la integridad física podría no compensar un daño patrimonial muy grande. Incluso podría suceder que fuera razonable estar dispuesto a perder la vida antes que perder todo el patrimonio. Vitoria, por ejemplo, afirma: "si un enfermo no puede tener la medicina [necesaria para conservar la vida] a menos que diera todo su patrimonio, entonces no considero que esté obligado a hacerlo" 22 .

Un tercer criterio para evaluar la gravedad de los males y de los bienes en sí mismos que parece estar presente en los escolásticos es el que podríamos denominar "relevancia de los números". Según este criterio, el número de vidas humanas salvadas o de muertes humanas evitadas es relevante para los juicios de proporcionalidad. Así, si un medicamento escaso pudiera salvar alternativamente a cinco personas (que necesitan pequeñas dosis) o solo a una (que necesita el total de la dosis disponible), lo razonable sería, ceteris paribus, repartir el medicamento entre las cinco, aceptando como efecto colateral la imposibilidad de salvar a la sexta. Aunque esto parece de sentido común, en la discusión filosófica reciente existen algunos autores que niegan la relevancia de los números ${ }^{23}$. Hasta donde llega mi conocimiento, ningún escolástico se planteó explícitamente este problema. Sin embargo, hay afirmaciones que permiten concluir que sí atribuyen relevancia al número de vidas o muertes en juego. Así, ya hemos visto que Francisco de Vitoria sostiene que, aunque en una guerra puede justificarse a veces la muerte de inocentes como un efecto colateral de atacar a los agresores, nunca puede justificarse un ataque en el que, para matar a unos pocos agresores, se deba causar también la muerte de muchos inocentes.

Un cuarto criterio para evaluar la gravedad de los males y de los bienes en sí mismos nos dice que, cuando se trata de un mismo bien que admite privaciones en diversos grados, una mayor privación es peor que una menor ${ }^{24}$. Los escolásticos sostienen que, respecto de los males corporales, la pérdida de la vida es un mal más grave que otros daños que afectan en menor medida el bien del cuerpo. En tal

\footnotetext{
${ }^{21}$ Vitoria, Francisco de, Commentaria in secundam secundae, q. 64, a. 1, n. 3.

22 Vitoria, Francisco de, Relección sobre la templanza, n. 9.

23 Por ejemplo: Taurek, John, "Should the Numbers Count?", Philosophy and Public Affairs 6 (1977), pp. 293-316.

${ }^{24}$ Para esta sistematización me baso en Finnis, John, Natural Law and Natural Rights, Oxford, Oxford University Press, 1980, p. 111.
} 
sentido, la muerte es un mal más grave que una mutilación, una mutilación es más grave que una lesión, una lesión más grave que un golpe, etc. Esta idea se aprecia claramente cuando tratan acerca del consejo del mal menor. En este contexto, Bartolomé de Las Casas sostiene que "quitar mal o [hacer] menos mal en alguna manera es hacer bien, según el Filósofo en sus Éticas. De aquí es que podemos aconsejar a uno que está aparejado para cometer algún gran mal o pecado grande, que se contente con hacer otro menor. Así como si estuviese uno determinado de matar a un clérigo, podríamosle aconsejar que se contentase con darle de palos. Y al usurero que al pobre no lleve como al rico tanta usura" ${ }^{25}$. En el mismo contexto, Domingo de Soto afirma que si un hombre está dispuesto a matar a otro es lícito aconsejarle que solo lo lesione o hiera ${ }^{26}$, de lo que se sigue que la herida y la lesión son males menores que la muerte. Esto, por supuesto, es bastante obvio y probablemente nadie lo discutiría. También es obvio, como lo muestra la última parte del texto de Las Casas, que la gravedad de los males patrimoniales debe contemplar la pérdida objetiva (conmensurable según unidades monetarias) y la condición económica de la persona que padece la pérdida.

Lo visto en el párrafo anterior nos permite extraer una conclusión importante. La existencia del principio del consulere minus malum, aceptado por todos los escolásticos, indica que dichos autores reconocen que los males pueden ser comparados entre sí. Ahora bien, como los males se definen por relación a los bienes de los que esos males son privación, se sigue que también es posible comparar entre sí los distintos bienes. Además de los criterios analizados en los párrafos precedentes, los escolásticos presentan otros criterios al comparar la malicia de algunas especies de pecados. No se acometerá aquí, sin embargo, el estudio de esos criterios, pues tienen poca relevancia para las materias jurídicamente relevantes. En cualquier caso, ninguna de las tesis de los escolásticos sugiere algo así como una pretensión de conmensurar o asignar valor numérico a bienes humanos fundamentales diversos entre sí.

Cerraré este apartado con algunos ejemplos. Conforme a la primacía del bien común sería proporcionado, por ejemplo, enviar soldados a la guerra para defender la patria, o, mediando justa compensación, expropiar bienes privados por causa de utilidad pública. Conforme a la primacía de las personas sería proporcionado, por ejemplo, preferir salvar de la muerte a un ser humano antes que salvar de la muerte a un perro (o salvar de la destrucción a un cuadro valioso), mientras que sería desproporcionado lo contrario. Del mismo modo, sería desproporcionado que, con

\footnotetext{
${ }^{25}$ Las Casas, Bartolomé de, Respuesta a las "Doce dudas" de Bartolomé de Vega, cap. 31.

26 Soto, Domingo de, De iustitia et iure, 1. 6, q. 1, a. 5.
} 
el fin de impedir la muerte de un perro (o la destrucción de un cuadro valioso), se realizara una acción de la que también se sigue como efecto la muerte de una persona. Conforme a la relevancia de los números sería proporcionado, por ejemplo, en paridad de otras condiciones, preferir salvar de la muerte a cinco personas antes que salvar a una, mientras que sería desproporcionado lo contrario. Del mismo modo, sería desproporcionado que, con el fin de impedir la muerte de una persona, se realizara una acción de la que también se sigue como efecto la muerte de cinco. Conforme al criterio de la privación gradual sería proporcionado, por ejemplo, en paridad de otras condiciones, preferir salvar a una persona de la muerte antes que salvar a otra de una lesión, mientras que sería desproporcionado lo contrario. Del mismo modo, sería desproporcionado que, con el fin de impedir que una persona resulte lesionada, se realizara una acción de la que también se sigue como efecto la muerte de otra. Conforme al criterio de los deberes especiales del agente sería proporcionado, por ejemplo, que un padre prefiera salvar de la muerte a su hijo antes que a un niño extrańo, mientras que sería desproporcionado lo contrario. Del mismo modo, sería desproporcionado que, con el fin de impedir la muerte de un nińo extraño, un padre realizara una acción de la que también se sigue como efecto la muerte de su propio hijo. Por último, conforme al criterio de la probabilidad sería proporcionado, en paridad de otras condiciones, preferir impedir un mal cierto antes que un mal solo probable de la misma gravedad, mientras que sería desproporcionado lo contrario. Del mismo modo, sería desproporcionado que, con el fin de impedir un mal solo probable, se realizara una acción de la que también se sigue como efecto un mal igualmente grave pero seguro. Además, este criterio también permite concluir que es proporcionado realizar una acción que impide un mal y causa otro cuando este último se producirá igualmente — por influjo de otra causa- si la acción se omite.

\section{Conclusiones}

LOS MORALISTAS Y JURISTAS DE LA ESCOLÁSTICA ESPAÑOla AURISECULAR desarrollaron un conjunto de criterios para formular juicios sobre la proporcionalidad de bienes y males. Para estos autores, los juicios de proporcionalidad entran en escena, principalmente, al momento de evaluar la licitud o ilicitud de acciones que producen efectos colaterales malos. En ningún caso los juicios de proporcionalidad constituyen el criterio exclusivo o supremo para evaluar la moralidad de los actos humanos. Los actos intrínsecamente malos constituyen un límite frente al cual cesa todo juicio de proporcionalidad. 
Los aportes de los escolásticos pueden resumirse en los seis puntos siguientes. Primero: en los escolásticos está implícita la idea de que los diversos bienes y males humanos no son conmensurables entre sí, por lo que no pueden ser reducidos a una unidad común que permita efectuar ponderaciones con exactitud matemática. En casos que involucran bienes humanos diversos, el juicio prudencial es siempre necesario. Segundo: los escolásticos piensan que los diversos bienes y males humanos sí pueden ser comparados (por lo menos en alguna medida), lo que permite sostener que algunos bienes son mayores que otros y algunos males son más graves que otros. Los juicios de proporcionalidad, por tanto, son posibles y necesarios. Tercero: un adecuado juicio de proporcionalidad debe evaluar (i) la importancia de los bienes y males considerados en sí mismos, (ii) la importancia de los bienes y males en relación con el agente y (iii) la probabilidad de la ocurrencia de los diversos bienes y males. Cuarto: al evaluar la importancia de los bienes y males considerados en sí mismos se puede afirmar que (a) el bien común es superior al bien particular, (b) el bien de las personas es superior al bien de las cosas, (c) es relevante el número de personas que padecerá cierto mal o que participará de cierto bien y (d) cuando se trata de un mismo bien que admite privaciones en diversos grados, una mayor privación es peor que una menor. Quinto: al evaluar la importancia de los bienes y males en relación con el agente se puede afirmar que, aunque dos bienes o dos males sean igual de importantes en sí, uno de ellos puede ser mayor para el agente en virtud de algún deber especial que derive de sus compromisos previos o de su estado u oficio. Sexto: al evaluar la probabilidad de la ocurrencia de los diversos bienes y males se puede afirmar que, entre dos bienes o dos males igual de importantes en sí mismos o en relación con el agente, es mayor el más seguro de ellos. 


\section{REFERENCIAS BibLIOGRÁFICAS}

Alexy, Robert, "Los derechos fundamentales y la proporcionalidad", trad. de Renate Hoffmann, en id., Ensayos sobre la teoría de los principios y el juicio de proporcionalidad, Lima, Palestra, 2019, pp. 237-250.

Alexy, Robert, "La dignidad humana y el juicio de proporcionalidad", trad. de María Quimbayo, en id., Ensayos sobre la teoría de los principios y el juicio de proporcionalidad, Palestra, Lima, 2019, pp. 281-295.

Azor, Juan, Institutionum moralium, Brixiae, Io. Baptistam Bozzolam, 1621.

Báńez, Domingo, Decisiones de iure et iustitia, Duaci, Petri Borremans, 1615.

Collegii salmanticensis ff. discalceatorum b. Mariae de Monte Carmeli primitivae observantiae, Cursus theologicus, Lugduni, Joannis Antonii Huguetan et soc., 1679.

Finnis, John, Natural Law and Natural Rights, Oxford, Oxford University Press, 1980.

Las Casas, Bartolomé de, Respuesta a las "Doce dudas" de Bartolomé de Vega, edición de J. B. Lassegue, Madrid, Alianza, 1992.

Nagel, Thomas, The View from Nowhere, New York, Oxford University Press, 1986.

Sánchez, Tomás, Opus morale in praecepta Decalogi, Lyon, Horatii Cardon, 1615.

Soto, Domingo de, De iustitia et iure, edición bilingüe de Marcelino González, Madrid, Instituto de Estudios Políticos, 1967-1968.

Suárez, Francisco, Commentaria in secundam secundae divi Thomae, scilicet de fide, de spe et de charitate disputationes, Parisiis, Ludovicum Vivés, 1858.

Taurek, John, "Should the Numbers Count?", Philosophy and Public Affairs, 6, 1977, pp. 293-316.

Villalobos, Enrique de, Summa de la theologia moral y canonica, Salamanca, Diego de Cussio, 1629.

Vitoria, Francisco de, De iure belli, Salamanca, San Esteban Editorial, 2017.

Vitoria, Francisco de, Commentaria in secundam secundae, Milwaukee, Marquette University Press, 1997.

Vitoria, Francisco de, Relección sobre la templanza, ed. castellana de Felipe Castañeda, Bogotá, Universidad de los Andes (Colombia), 2007.

DOI: https://doi.org/10.15366/bp2021.26.001

Bajo Palabra. II Época. No26. Pgs: 21-38 
